\title{
Parâmetros geomorfométricos para análise da suscetibilidade a movimentos de massa na área urbana de Blumenau, Santa Catarina
}

\author{
Geomorfometric parameters in the analysis of mass movement \\ susceptibility in the Blumenau's urban zone, Santa Catarina
}

\author{
Tanice Cristina Kormann'; Luís Eduardo de Souza Robaina ${ }^{\text {II }}$
}

\begin{abstract}
RESUMO
Esta pesquisa objetiva apresentar uma proposta de caracterização do relevo da área urbana de Blumenau a partir da determinação da forma das vertentes utilizando os parâmetros geomorfométricos de declividade, plano e perfil de curvatura a fim de determinar suscetibilidade a movimentos de massa. O município está situado na porção nordeste do estado de Santa Catarina, região sul do Brasil. A análise parte do cruzamento de dados geoespaciais relativos aos atributos topográficos utilizando procedimentos automatizados em ambiente de Sistemas de Informação Geográfica (SIG). A ocorrência histórica de eventos causadores de danos foi determinada a partir de dados da defesa civil municipal. A compartimentação geomorfométrica permitiu identificar oito unidades de relevo, sendo a Unidade VIII a que combina as condições de maior suscetibilidade à ocorrência de movimentos de massa: declividade superior a $30 \%$, perfil côncavo e plano convergente. Os bairros que apresentam maior frequência de ocorrência da Unidade VIII são: Da Glória, Velha Grande, Ribeirão Fresco, Nova Esperança e Bom Retiro.
\end{abstract}

Palavras-chave: Árvore de decisão; Geomorfometria; Suscetibilidade a movimentos de massa

\section{ABSTRACT}

This researche have the objective presents a proposal to characterize the relief of the urban area of Blumenau, by determining the shape of the slopes using the geomorphometric parameters of declivity, plane and profile of curvature in order to determine susceptibility to mass movements. The municipality is located in the northeastern portion of the Santa Catarina, southern region of Brazil. This technique seeks to classify the relief from the crossing of geospatial data related to topographic attributes using automated procedures in a Geographic Information Systems (GIS). The occurrence historical of events causing damage was determined from municipal civil defense data. The geomorphometric compartmentalization allowed to identify eight relief units, with Unit VIII combining the conditions of greatest susceptibility to the occurrence of mass movements: declivity greater than $30 \%$, concave profile and convergent plane. The neighborhoods that present the highest frequency of Unit VIII are: Da Glória, Velha Grande, Ribeirão Fresco, Nova Esperança and Bom Retiro.

Keywords: Decision tree; Mass movement; Geomorphometry; Susceptibility

IDoutoranda do Programa de Pós-Graduação em Geografia da Universidade Federal do Rio Grande do Sul. E-mail: tanice.kormann@gmail.com ORCID: https://orcid.org/0000-0003-4897-5811

II Professor do Departamento de Geociências da Universidade Federal de Santa Maria. E-mail: lesrobaina@yahoo.com.br ORCID: https://orcid.org/0000-0002-2390-6417 


\section{INTRODUÇÃO}

Os desastres naturais são tidos como resultado da ocorrência de processos da dinâmica superficial que causam danos à sociedade. São mais frequentes na faixa oriental do território brasileiro (FERNANDES e AMARAL, 1996). Dentre os desastres naturais que afetam o Brasil os movimentos de massa são responsáveis pelo maior número de vítimas fatais (CARVALHO e GALVÃO, 2006; TOMINAGA, 2009).

Os processos de movimentos de massa são significativos no modelado do relevo terrestre (BIGARELLA et al., 2003; TOMINAGA, 2009), resultando da mobilização de material (solo/rocha) sobre a ação da gravidade em que o principal agente deflagrador nos climas tropicais úmidos é a água. Apesar de ser um processo de origem natural pode ser induzido pela ação humana que altera a situação de equilíbrio da encosta (FERNANDES \& AMARAL, 1996; ROBAINA, 2008; NUNES, 2015).

O município de Blumenau possui uma convivência histórica com desastres naturais. O Atlas dos Desastres Naturais no Estado de Santa Catarina (HERRMANN, 2006) aponta Blumenau como o município que apresentou o maior número de movimentos de massa e inundações no inventário de eventos ocorridos entre 1980 e 2003. Para além deste histórico, episódios recentes corroboram com os resultados encontrados no Atlas.

Em novembro de 2008 a ocorrência de episódios extremos de precipitação desencadearam sérios danos associados à ocorrência generalizada de movimentos de massa e enxurradas levando a decretação de Situação de Calamidade Pública no município (BLUMENAU, 2008). Este evento passa a ser considerado um novo paradigma regional para abordagem do assunto devido às proporções dos danos, resultando na morte de 24 pessoas (POZZOBON, 2013; AVILA e MATTEDI, 2017). Ainda em 2011, dois episódios de precipitação localizada resultaram em dois Decretos de Situação de Emergência em um intervalo de tempo inferior a dois meses (BLUMENAU, 2011a; BLUMENAU, 2011b).

O conhecimento das formas e a compreensão dos processos da dinâmica superficial são essenciais para o planejamento dos sítios urbanos visto que o relevo é 
o suporte físico de interações naturais e sociais. Desta forma, o planejamento faz uso do geoprocessamento como ferramenta que permite a integração de diferentes bases de dados espaciais, o que tem contribuído para otimizar a tomada de decisão quanto à gestão territorial (SILVA e ZAIDAN, 2004; FLORENZANO, 2008). O desenvolvimento de métodos automáticos de extração de informações ambientais a partir de uma crescente disponibilidade de dados se reflete no constante aprimoramento das técnicas de análise digital, permitindo a extração automática de variáveis topográficas (VALERIANO, 2003).

A adoção de métodos computacionais para caracterização do relevo pode ser efetuada a partir de seus atributos, que podem ser extraídos por meio de um Modelo Digital do Terreno (MDT). O MDT consiste em uma descrição matemática do terreno realizada por meio de interpolação (ROCHA, 2000). A análise do relevo por meio de variáveis geomorfométricas corresponde a um procedimento digital que considera os dados derivados de um MDT como atributos topográficos (MOORE et al., 1991). Originado do termo em inglês geomorphometry (McBRATNEY et al., 2003; SILVEIRA et al., 2013) é uma técnica que permite a diferenciação de porções nas encostas sujeitas a diferentes tipos de processos.

Esta pesquisa tem início com uma caracterização do relevo do sítio urbano de Blumenau que tem o objetivo de apresentar a área de estudo e contextualizar a problemática. Na sequência será apresentada a caracterização das variáveis geomorfométricas (declividade, plano e perfil de curvatura) que permitem identificar as áreas mais propícias a ocorrências de processos de movimentos de massa para o perímetro urbano municipal. Por fim, os resultados são analisados de forma comparativa ao histórico de ocorrências atendidas pela Defesa Civil Municipal.

\section{MATERIAIS E MÉTODOS}

A elaboração dos mapas de caracterização do sítio urbano e a classificação geomorfométrica utilizou como insumos os dados da base planialtimétrica do município de Blumenau. Estes dados resultam da restituição de levantamento 
aerofotogramétrico na escala 1:10.000 (AEROIMAGEM S/A, 2003) que deu origem as curvas de nível em arquivo shapefile no formato vetorial com intervalos de $5 \mathrm{~m}$ cedidas pelo setor de Cartografia da Prefeitura Municipal de Blumenau.

De posse dessa informação, a geração do Modelo Digital do Terreno (MDT) ocorreu a partir da interpolação por meio da rede triangular irregular (TIN), procedimento realizado no software Arc Gis 10.4.1®. Este procedimento resultou em dados contínuos (em formato matricial) que serviram de base para obtenção dos parâmetros de declividade e forma da vertente (plano e perfil de curvatura), utilizados na compartimentação geomorfométrica do relevo.

As informações referentes a altimetria foram segmentadas em 8 classes com base na observação do histograma de dados, adotando o critério da quebra de continuidade para estabelecer os seguintes intervalos: 5 - 100 m, $101-180$ m, 181 260 m, 261 m - 350 m, $351-470$ m, $471-600$ m, $601-730$ m e $731-980$ m.

A declividade ganha significativa importância como parâmetro na indicação de processos naturais ao ser incorporada pela legislação que regulamenta o parcelamento do solo através da Lei Lehman (BRASIL, 1979). Desta forma, o presente estudo considera a inclinação de $30 \%$ como valor de corte diante do estabelecimento de restrições a ocupação de encostas em declives superiores ao estipulado.

Apesar da divergência entre autores quanto ao valor da declividade, é consenso que essa não deve ser tomada como único parâmetro. Neste sentido, as informações do plano e perfil de curvatura das vertentes foram analisadas por meio dos valores de curvatura existentes no histograma de frequência. Valores positivos representam vertentes divergentes enquanto valores negativos correspondem ao plano de curvatura convergente. Valores de curvatura positivos correspondem a vertentes côncavas enquanto valores negativos são encontrados em vertentes convexas (VALERIANO e CARVALHO JÚNIOR, 2003). A declividade e curvaturas no plano e em perfil foram as variáveis cruzadas na árvore de decisão que definiu as unidades da compartimentação geomorfométrica (Figura 01). 
Figura 1 - Esquema ilustrativo da árvore de decisão.

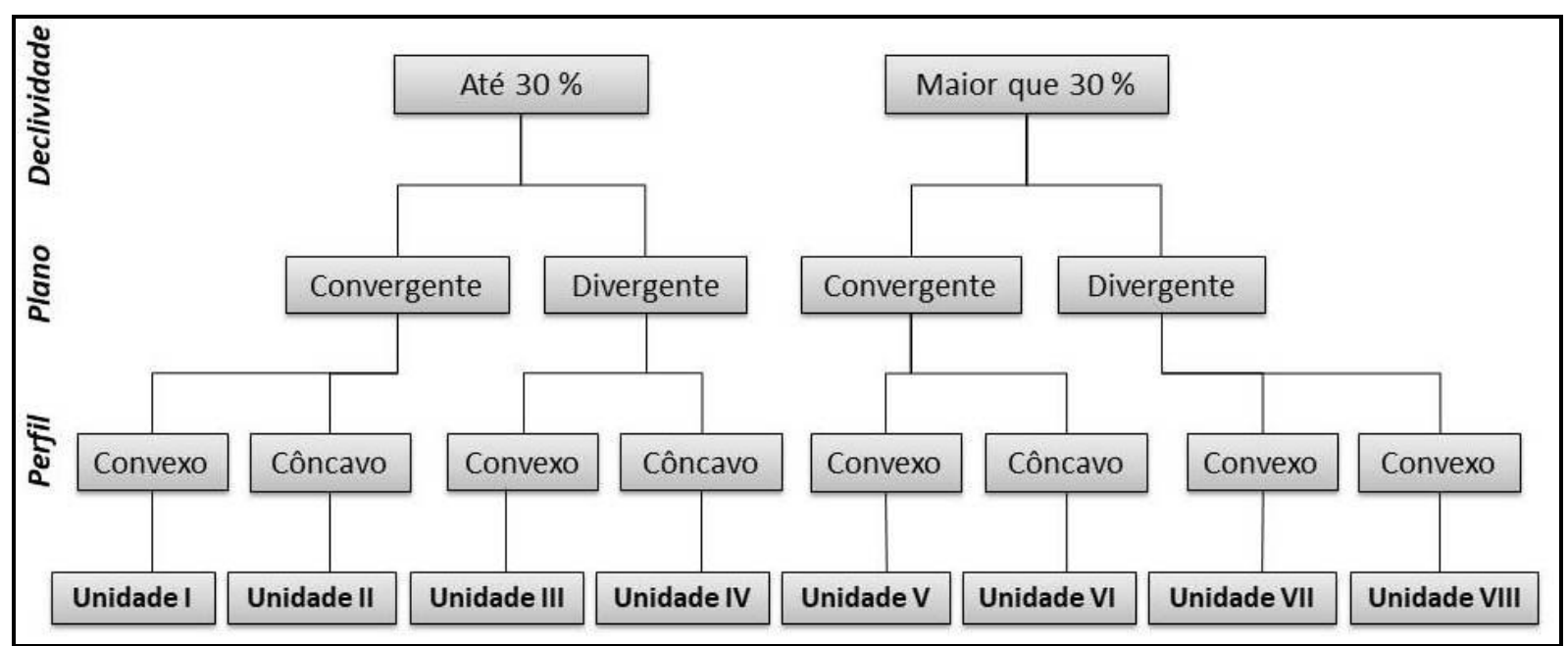

Fonte: Organização dos autores.

Os resultados da compartimentação geomorfométrica permitiram a identificação dos bairros mais suscetíveis a processos de movimento de massa, os quais foram analisados comparativamente aos dados de ocorrências atendidas pela Defesa Civil Municipal considerando o período de 1997 a 2015 em função da disponibilidade dos dados.

\section{RESULTADOS E DISCUSSÕES}

O município de Blumenau está situado no nordeste do estado de Santa Catarina, com seu território predominantemente inserido na Bacia Hidrográfica do Rio Itajaí-Açu. Trata-se da maior rede de drenagem da vertente Atlântica (Figura 02). Sua importância se reflete no processo de ocupação do território que se estruturou a partir dos principais cursos d'água na segunda metade do século XIX.

De acordo com o último Censo Populacional (IBGE, 2010), Blumenau é o terceiro município mais populoso do estado de Santa Catarina e o que possui maior número de habitantes vivendo em aglomerados subnormais. Este conceito foi usado primeiramente no Censo de 1991 para se referir ao conjunto de, ao menos, 51 unidades habitacionais carentes de serviços públicos essenciais, sendo o terreno de propriedade alheia (pública ou particular) com disposição geralmente desordenada 
6 | Parâmetros geomorfométricos para análise da suscetibilidade a movimentos de massa na área urbana de Blumenau, Santa Catarina

das vias e dos lotes, que não obedecem as diretrizes de planejamento urbano, geralmente constituindo área de acentuada densidade populacional (IBGE, 2010).

Figura2 - Mapa de localização do município de Blumenau com a altimetria e a rede de drenagem da Bacia Hidrográfica do Rio Itajaí-Açú, região nordeste de Santa Catarina.
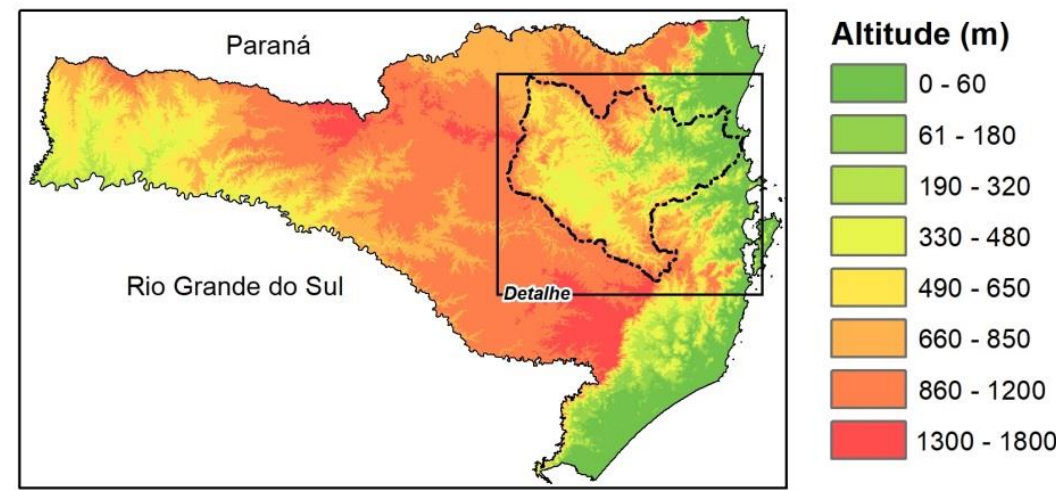

Legenda

$\sim$ Cursos d'água

3 Limite Municipal

Bacia Hidrográfica do

-.." Itajaí-Açú

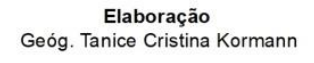

Parâmetros Cartográficos Sistema de Coordenadas Geográficas Datum SIRGAS 2000

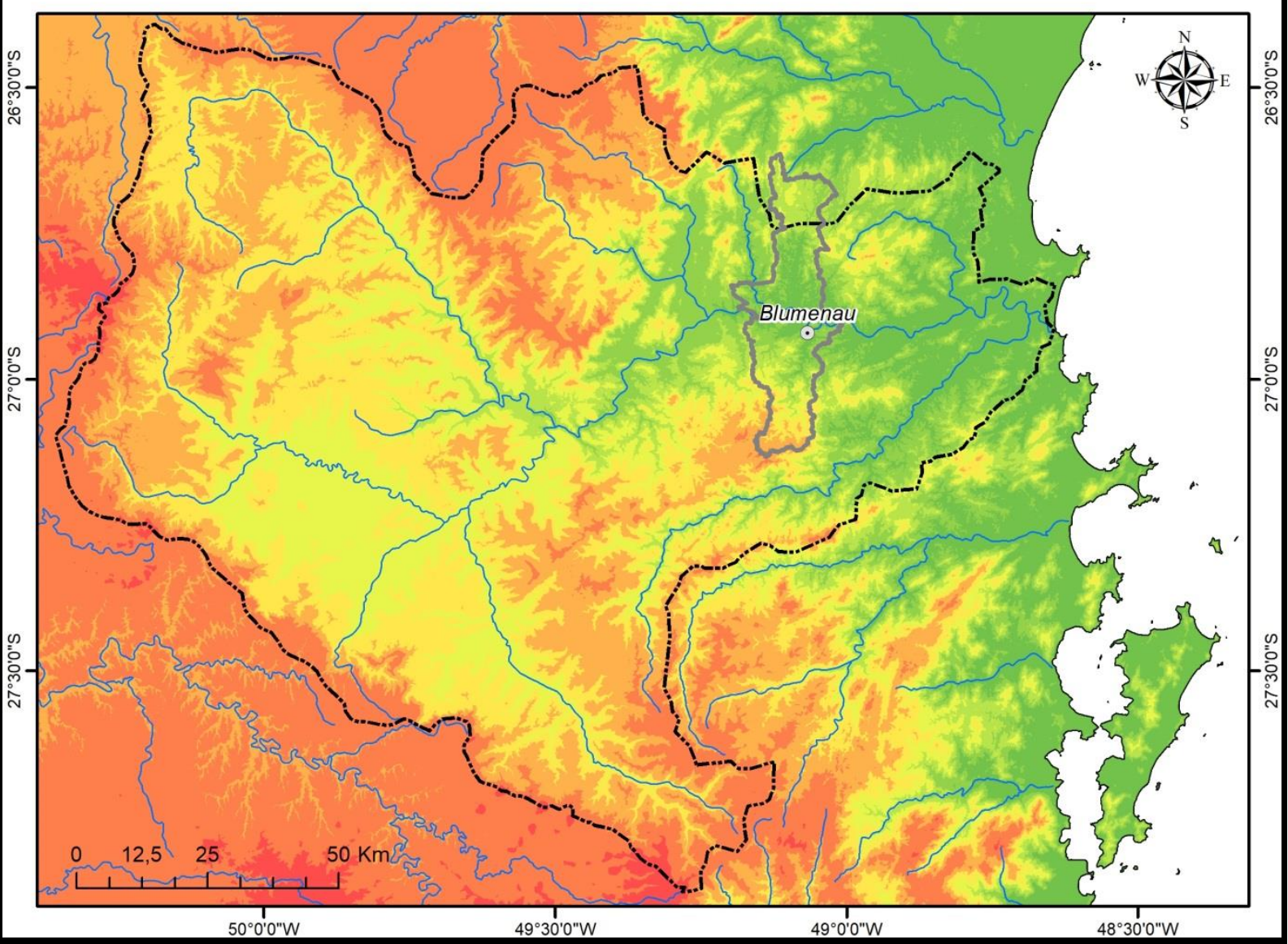

Fonte: Organização dos autores.

\subsection{Relevo do sítio urbano de Blumenau}

O Rio Itajaí-Açu divide a malha urbana em duas porções de quase mesmo tamanho. De modo geral, a porção norte apresenta uma estrutura geológica mais 
estável, composta por rochas mais antigas e desgastadas do embasamento cristalino. Na porção sul há maior instabilidade em função da ocorrência de um intenso sistema de falhas que resultam na alternância de formações sedimentares de baixo grau de metamorfismo intercaladas por intrusões de corpos graníticos.

Essa significativa complexidade geológica da porção sul do território se reflete no relevo. O município de Blumenau apresenta significativa amplitude altimétrica, com as cotas mais baixas situadas na porção central do município enquanto as maiores elevações ultrapassam a cota de 980 m junto a Serra do Itajaí, no extremo sul do município, onde os divisores de água correspondem aos limites com outros municípios (Figura 03).

O mapa altimétrico permite observar que o perímetro urbano não ultrapassa a cota de $470 \mathrm{~m}$, fato que tem relação com o processo de povoamento que se deu nas proximidades dos cursos d'água. Esse processo resultou na mancha urbana que se estrutura a partir das menores altitudes, sendo condicionada pelo relevo, o que é especialmente visível na porção sul do território.

Predominam altitudes de até $100 \mathrm{~m}$, correspondendo a 37,01\% do território municipal. Essa faixa de altitude ocorre predominantemente na porção norte, enquanto as maiores altitudes ocorrem predominantemente na Bacia do Ribeirão Garcia. Situada na porção sul, a Bacia do Ribeirão Garcia apresenta as maiores amplitudes altimétricas responsáveis pela formação de vales profundos em " $V$ " esculpidos por uma drenagem encaixada (SANTOS, 1996). Ao contrário, os vales na porção norte são mais abertos, o que está associado ao predomínio de menores altitudes principalmente no Vale do Ribeirão Itoupava.

Essas diferenças podem ser visualizadas por meio da comparação de perfis altimétricos da porção norte (A-B) e sul (C-D) do município, ambos no sentido Norte - Sul (Figura 04). A comparação evidencia as distintas condições de relevo das duas porções do município; enquanto na porção norte o relevo encontra-se mais desgastado, com a Serra da Itoupava se destacando, a porção ao sul apresenta maior amplitude altimétrica indicando morfogênese mais intensa.

No estudo de processos da dinâmica superficial a declividade é um dos principais parâmetros utilizados (FERNANDES et al., 2001). Guerra e Cunha (1996) apontam que estudos realizados na serra do mar paulista indicam a deflagração de movimentos de massa a partir de declives de 20\%. Fernandes et al. (2001) em 
estudo no Serra da Tijuca apontaram o aumento do potencial de ocorrências de movimentos de massa crescente com o aumento da declividade até a classe de 370 $55^{\circ}$.

Figura 3 - Mapa altimétrico de Blumenau com indicação dos perfis altimétricos.

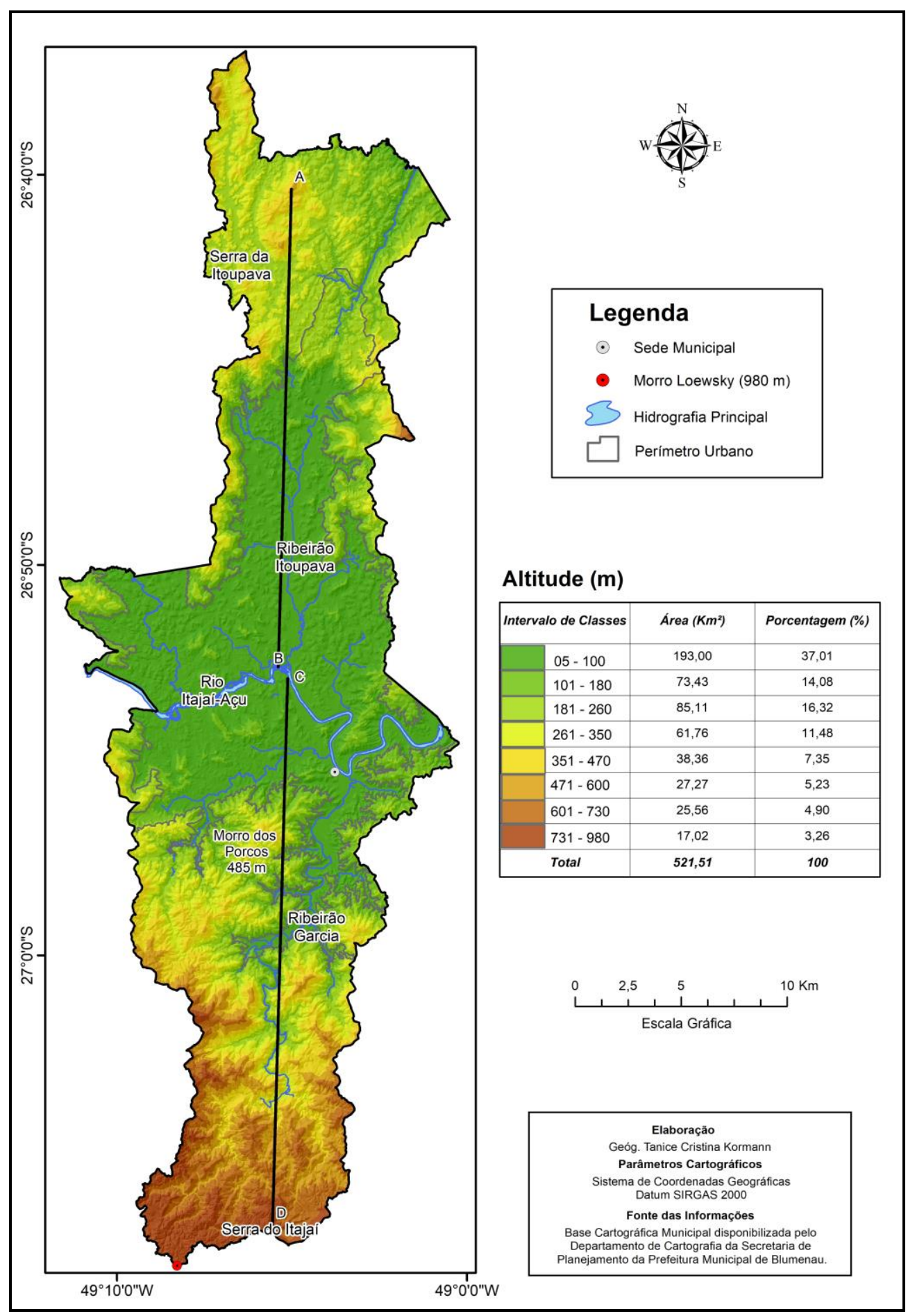

Fonte: Organização dos autores.

A figura 05 apresenta a distribuição espacial das declividades maiores e menores que $30 \%$ para o município de Blumenau. O mapa de declividades indica 
elevada frequência de declividades acentuadas. Se considerarmos todo o território municipal tem-se que $55,35 \%$ corresponde a declividades superiores a $30 \%$. Cabe ressaltar que a maior parte dessas situações ocorre na porção sul do município.

Figura 4 - Perfil altimétrico A - B situando na porção norte e perfil altimétrico C - D ilustrando porção sul do município de Blumenau.

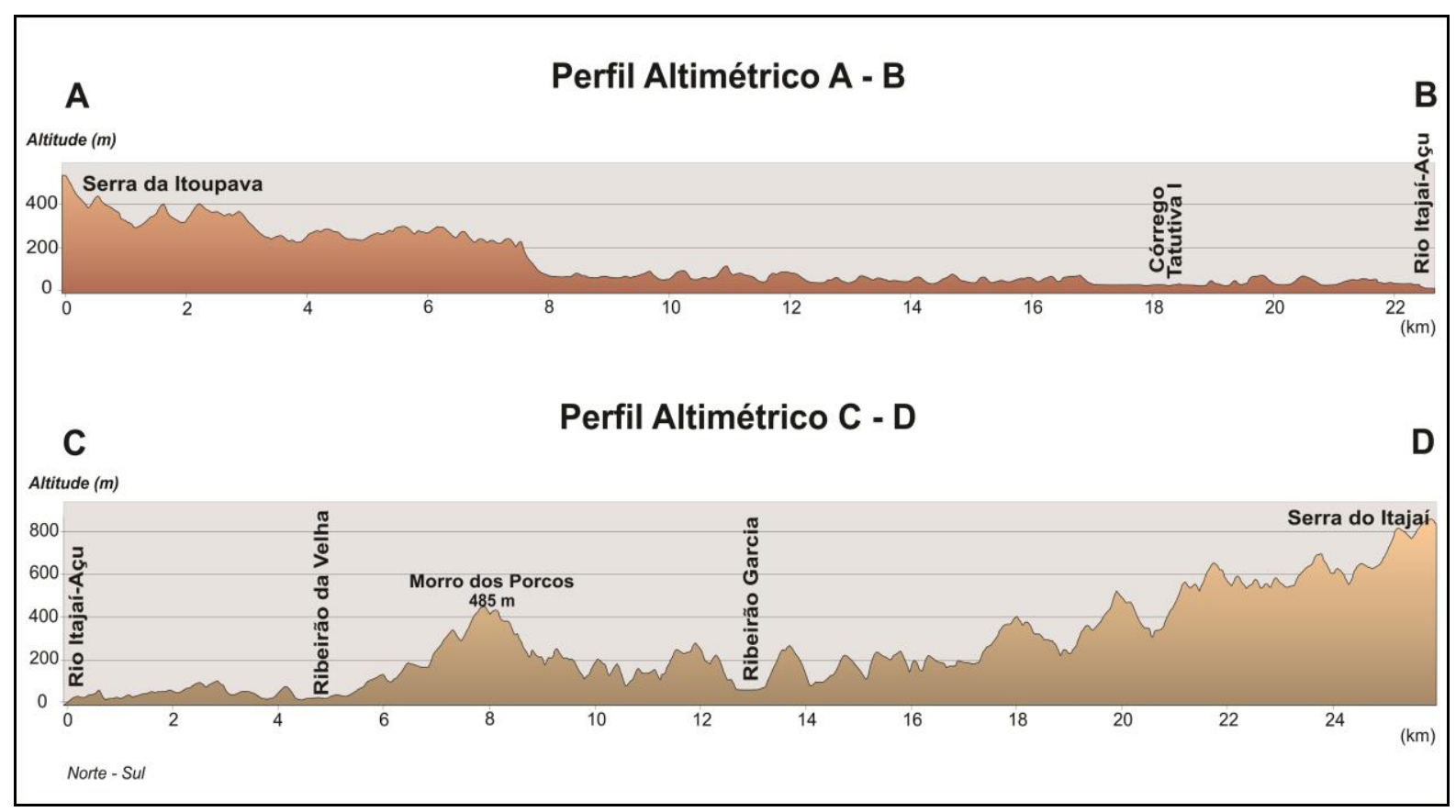

Fonte: KORMANN (2014).

Levando em consideração apenas a área urbana, o percentual de inclinações compreendidas no intervalo de 0 a $30 \%$ é de $70,72 \%$. Por outro lado, $29,28 \%$ da área urbana municipal apresenta encostas com inclinações superiores a 30\%, ou seja, com restrições a ocupação. Esta constatação permite considerar que mesmo dentro da área urbana há significativo percentual de setores que apresentam restrições a ocupação em função do relevo, fato indicativo da acentuada suscetibilidade a processos de movimentos de massa.

\subsection{Compartimentação geomorfométrica das encostas}

Diversos estudos de cunho geomorfológico têm chamado a atenção para o papel desempenhado pelas porções de convergência dos fluxos de água, tanto em superfície quanto em sub-superfície (DUNNE, 1970; COELHO NETTO, 1999; DIETRICH \& DUNNE, 1993; FERNANDES et al., 2001). Trabalhando especificamente com processos de movimentos de massa diversos autores têm comprovado que porções 
10 | Parâmetros geomorfométricos para análise da suscetibilidade a movimentos de massa na área urbana de Blumenau, Santa Catarina

da encosta onde há convergência de fluxo da água tendem a apresentar maiores registros de movimentos de massa (POZZOBON, 2013; GONÇALVES e FRANCISCO, 2016).

Figura 5 - Mapa de declividade enfatizando a área urbana de Blumenau.

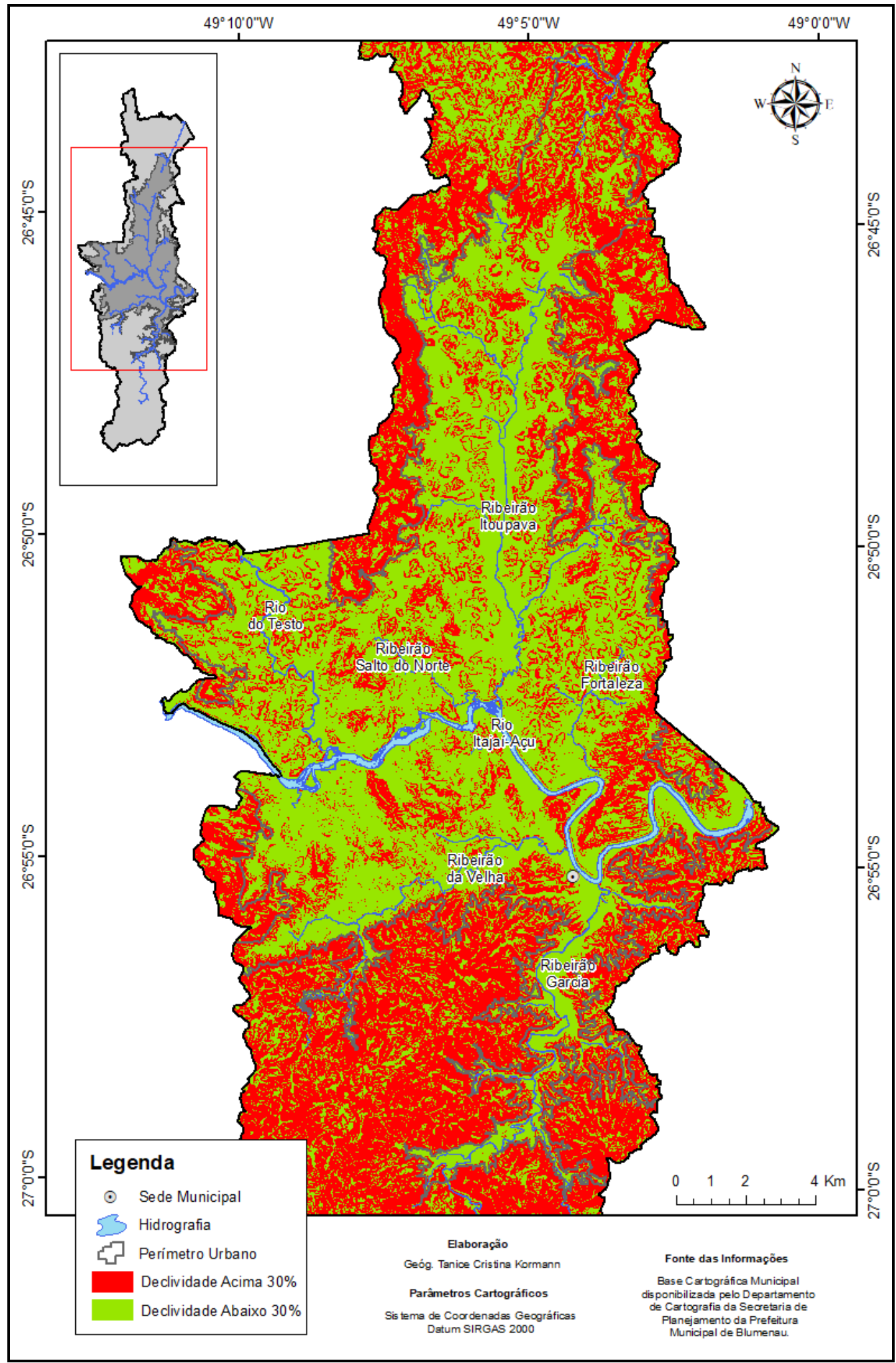

Fonte: Organização dos autores. 
Neste sentido, a caracterização da forma das encostas empregou informações do plano e do perfil de curvatura. O plano de curvatura se refere ao caráter divergente/convergente dos fluxos de matéria sobre o terreno quando analisado em projeção horizontal (VALERIANO e CARVALHO JÚNIOR, 2003). O perfil de curvatura refere-se ao caráter convexo/côncavo do terreno (VALERIANO, 2003).

A análise das encostas que compõem a área urbana de Blumenau foi baseada no estudo da inclinação e forma, a partir de agrupamentos formados em um diagrama em árvore. Como resultado obteve-se um total de 8 unidades, com suas respectivas frequências (Tabela 01) e distribuição espacial (Figura 06).

Tabela 1 - Frequência das oito unidades para a área urbana de Blumenau.

\begin{tabular}{|c|c|c|}
\hline Unidades & Área (ha) & Porcentagem (\%) \\
\hline Unidade I & $3.985,58$ & $19,96 \%$ \\
\hline Unidade II & $1.996,61$ & $10,00 \%$ \\
\hline Unidade III & $3.395,35$ & $17,00 \%$ \\
\hline Unidade IV & $4.701,79$ & $23,54 \%$ \\
\hline Unidade V & $1.999,77$ & $10,01 \%$ \\
\hline Unidade VI & 942,35 & $4,72 \%$ \\
\hline Unidade VII & $1.330,87$ & $6,66 \%$ \\
\hline Unidade VIII & $1.617,15$ & $8,10 \%$ \\
\hline Total & $19.969,46$ & 100 \\
\hline
\end{tabular}

Fonte: Organização dos autores.

As unidades I, II, III e IV correspondem às porções de relevo com declividades de até $30 \%$, sendo consideradas com menor potencial de ocorrência de processos de movimentos de massa. Dentre essas, as Unidade I e Unidade III representam porções de encosta menos favoráveis a ocorrência de processo de movimentos de massa já que nas formas divergentes o fluxo tende a ser mais disperso.

Comparativamente, encostas de perfil côncavo (Unidade III) são mais suscetíveis a processos de movimentos de massa que as encostas de perfil convexo (Unidade I). As encostas representadas pela unidade I ocorrem em 19,96\% da área urbana municipal, sendo a segunda unidade mais frequente, enquanto as da unidade III ocorrem em $17 \%$ da área urbana. 
12 | Parâmetros geomorfométricos para análise da suscetibilidade a movimentos de massa na área urbana de Blumenau, Santa Catarina

Figura 6 - Mapa da compartimentação geomorfométrica da área urbana de Blumenau

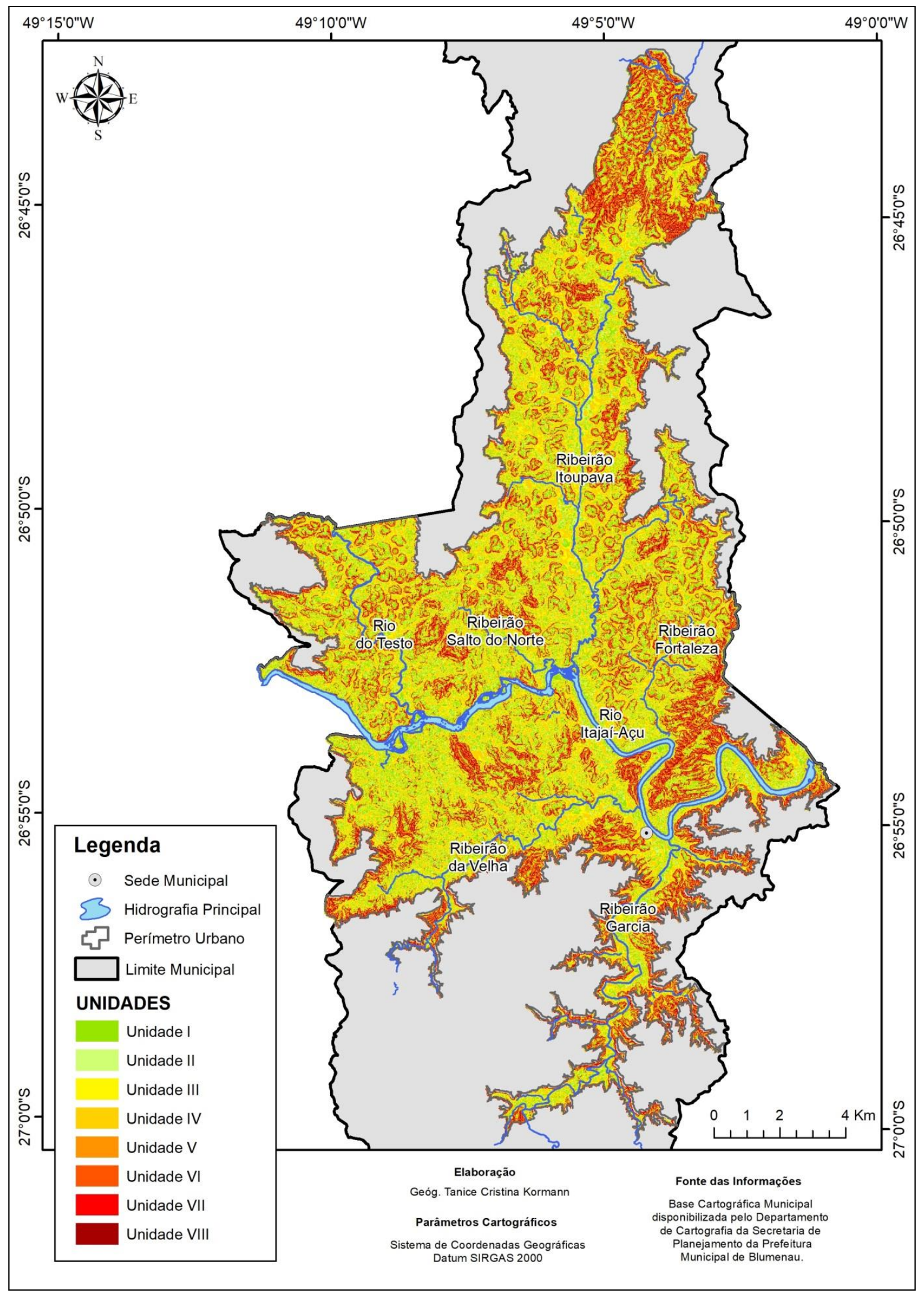

Fonte: Organização dos autores. 
As unidades II e IV representam as encostas com fluxo convergente, o que é indicado pelo plano de curvatura, e perfil convexo na primeira e côncavo na segunda. A unidade II ocorre em $10 \%$ da área urbana municipal, enquanto a unidade IV é a mais frequente, ocorrendo em $23,54 \%$ do perímetro urbano municipal. Apesar dos baixos valores de declividade destaca-se que a combinação de perfil de curvatura côncavo e plano de curvatura convergente da unidade IV permite concentração do fluxo de água na vertente. Tal combinação pode desencadear processos associados a transporte de material ou fluxos hídricos.

As unidades V, VI, VII e VIII representam encostas com declividades superiores a $30 \%$, sendo as mais suscetíveis a processos de movimentos de massa. Diante da predisposição a ocorrência de movimentos de massa nesta faixa de declividade, a realização de cortes e aterros tende a instabilizar a encosta. Desta forma, a Lei Lehman (BRASIL, 1979) estabelece restrições a incorporação destas áreas para a implantação de moradias.

Dentre as maiores inclinações, as unidades V e VII são menos suscetíveis por apresentarem fluxos divergentes. A unidade $V$ está presente em $10,01 \%$ da área urbana e é a menos suscetível que a unidade VII, que ocorre em pouco mais de 6\% da área urbana municipal. Considerando todas as combinações de características de relevo, as formas que apresentam convergência de fluxo são as mais suscetíveis e estão representadas pelas unidades VI e VIII, sendo que a primeira ocorre em somente $4,72 \%$ da área urbana. Para estas duas unidades, a unidade VIII apresenta as condições mais suscetíveis à ocorrência de movimentos de massa, ocorrendo em $8,10 \%$ da área urbana.

\subsection{Bairros com maior área de ocorrência da Unidade VIII}

A unidade VIII reúne as condições mais propensas a ocorrência de processos de movimentos de massa já que engloba as maiores inclinações, perfil côncavo e plano convergente, fatores que contribuem parra aceleração dos processos e concentração do fluxo hídrico. Desta forma, esta unidade é tomada como base para a identificação dos bairros com maior suscetibilidade à ocorrência de movimentos de massa. Os cinco bairros que apresentaram maior percentual de ocorrência da 
Unidade VIII são apresentados no mapa da Figura 07 enquanto o percentual de cada unidade é detalhado na Tabela 02.

Os bairros Velha Grande e Nova Esperança foram criados com a Lei Complementar no. 489, de 25/11/2004 (BLUMENAU, 2004) que estabeleceu a nova divisão bairros resultando em um total de 35 enquanto o perímetro urbano anterior contava com 30. Cabe considerar que a alteração no limite destes bairros prejudica a análise do histórico de ocorrências atendidas pela Defesa Civil.

O bairro Velha Grande foi desmembrado a partir do antigo bairro da Velha, que aparece no histórico como o bairro com maior número de ocorrências atendidas pela Defesa Civil Municipal, totalizando 718 para o período de 19 anos de registros. 0 bairro Nova Esperança foi criado a partir de uma fração do Fortaleza e parte do Ponta Aguda além de novas áreas incorporadas ao perímetro urbano municipal. Os bairros Fortaleza e Ponta Aguda são, respectivamente, o quarto e o quinto maior frequência de ocorrência de movimentos de massa atendidos pela Defesa Civil Municipal (com 414 e 318 registros respectivamente).

O elevado número de ocorrências de movimentos de massa para os bairros Velha Grande e Nova Esperança indica a combinação da suscetibilidade com condição de vulnerabilidade social. Tal informação encontra respaldo nos dados do IBGE que indicam a existência de áreas definidas como aglomerados subnormais. O bairro Da Glória se destaca com um total de 20,69\% de sua área correspondente a Unidade VIII, aparece no histórico de ocorrências da Defesa Civil Municipal como sétimo com mais registros, totalizando 229 atendimentos relativos a movimentos de massa para um período de 19 anos de dados.

Os bairros Ribeirão Fresco e Bom Retiro apresentam menos registros de ocorrência de movimentos de massa (respectivamente 58 e 23 registros) quando comparados com os bairros mencionados anteriormente. Ambos têm seu processo de ocupação motivado pela proximidade em relação ao centro urbano. Especificamente no Bom Retiro o processo de ocupação está associado à instalação da área da Indústria Hering que há mais de um século se implanta no local, o que acarreta numa diminuição de espaço destinados para ocupação residencial. O menor número de ocorrências atendidas pela Defesa Civil municipal nestes bairros também pode ser explicado pelo menor percentual de área dos bairros ou ainda pela subnotificação. 
Figura 7- Mapa da compartimentação geomorfométrica para os cinco bairros com maior percentual de áreas da Unidade VIII.
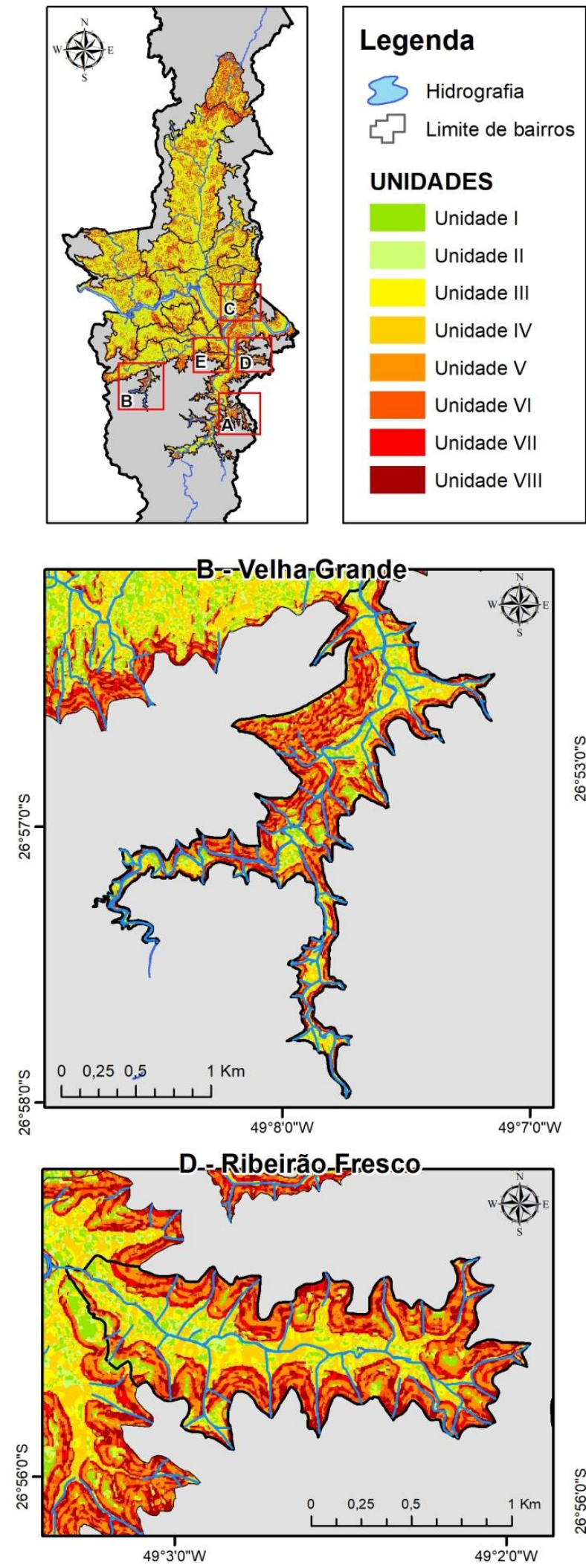

Fonte: Organização dos autores.
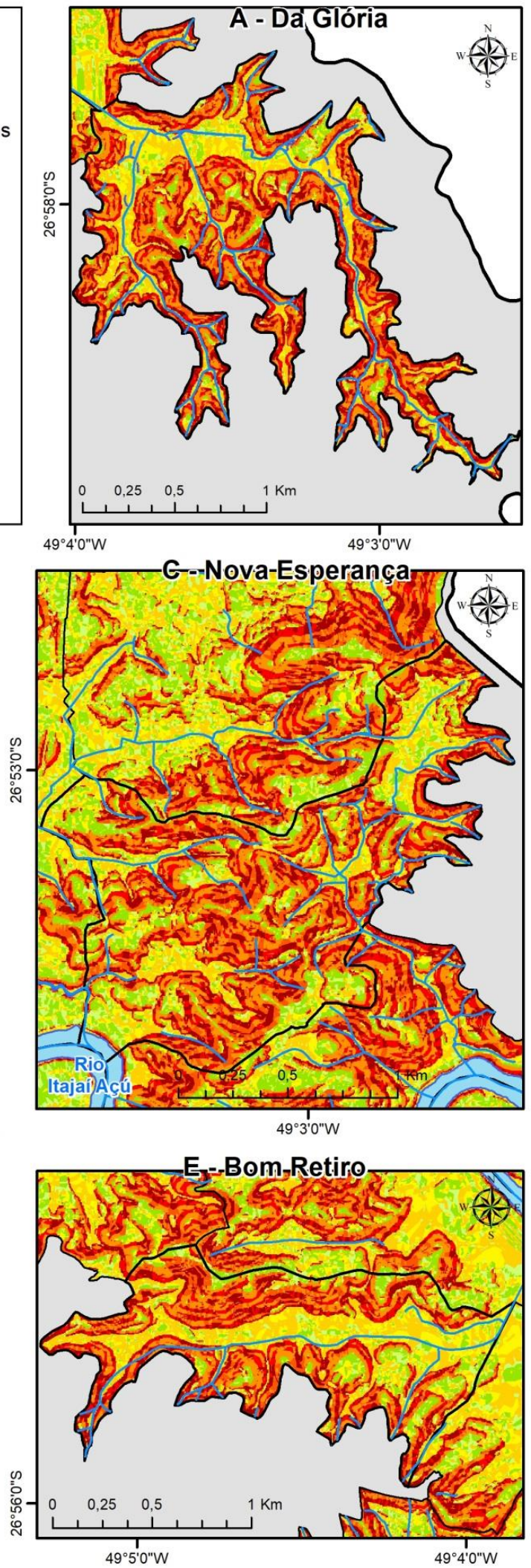
Tabela 2 - Distribuição das Unidades nos bairros com maior percentual de áreas da Unidade VIII.

\begin{tabular}{|c|c|c|c|c|c|}
\hline Bairros & Unidade & Área (ha) & Percentual & & Declividade \\
\hline \multirow{9}{*}{ DA GLÓRIA } & Unidade I & 11,34 & $5,86 \%$ & \multirow{4}{*}{$\begin{array}{l}\text { oे } \\
\text { Oे } \\
\text { 过 }\end{array}$} & \multirow{4}{*}{$34,57 \%$} \\
\hline & Unidade II & 6,04 & $3,12 \%$ & & \\
\hline & Unidade III & 16,85 & $8,70 \%$ & & \\
\hline & Unidade IV & 32,73 & $16,90 \%$ & & \\
\hline & Unidade V & 38,08 & $19,66 \%$ & \multirow{4}{*}{ 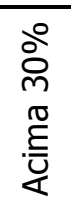 } & \multirow{4}{*}{$65,43 \%$} \\
\hline & Unidade VI & 17,76 & $9,17 \%$ & & \\
\hline & Unidade VII & 30,84 & $15,92 \%$ & & \\
\hline & Unidade VIII & 40,07 & $20,69 \%$ & & \\
\hline & Total & 193,70 & $100,00 \%$ & & \\
\hline \multirow{9}{*}{$\begin{array}{c}\text { VELHA } \\
\text { GRANDE }\end{array}$} & Unidade I & 13,84 & $8,56 \%$ & \multirow{4}{*}{$\begin{array}{l}\text { Oे } \\
\text { Oे } \\
\text { 艺 }\end{array}$} & \multirow{4}{*}{$43,99 \%$} \\
\hline & Unidade II & 7,73 & $4,78 \%$ & & \\
\hline & Unidade III & 18,95 & $11,72 \%$ & & \\
\hline & Unidade IV & 30,60 & $18,93 \%$ & & \\
\hline & Unidade V & 27,50 & $17,01 \%$ & $\rho^{\circ}$ & \multirow{4}{*}{$56,01 \%$} \\
\hline & Unidade VI & 12,18 & $7,53 \%$ & m & \\
\hline & Unidade VII & 22,83 & $14,12 \%$ & $\stackrel{\widetilde{E}}{E}$ & \\
\hline & Unidade VIII & 28,04 & $17,35 \%$ & $\overline{\bar{Q}}$ & \\
\hline & Total & 161,66 & $100,00 \%$ & & \\
\hline \multirow{9}{*}{$\begin{array}{l}\text { RIBEIRÃO } \\
\text { FRESCO }\end{array}$} & Unidade I & 9,34 & $7,68 \%$ & \multirow{4}{*}{ 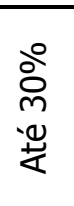 } & \multirow{4}{*}{$41,76 \%$} \\
\hline & Unidade II & 5,73 & $4,72 \%$ & & \\
\hline & Unidade III & 13,59 & $11,18 \%$ & & \\
\hline & Unidade IV & 22,11 & $18,18 \%$ & & \\
\hline & Unidade V & 23,22 & $19,09 \%$ & \multirow{4}{*}{ 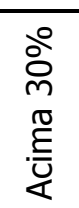 } & \multirow{4}{*}{$58,24 \%$} \\
\hline & Unidade VI & 10,13 & $8,33 \%$ & & \\
\hline & Unidade VII & 16,43 & $13,52 \%$ & & \\
\hline & Unidade VIII & 21,03 & $17,30 \%$ & & \\
\hline & Total & 121,59 & $100,00 \%$ & & \\
\hline \multirow{9}{*}{$\begin{array}{c}\text { NOVA } \\
\text { ESPERANÇA }\end{array}$} & Unidade I & 22,11 & $12,03 \%$ & \multirow{4}{*}{ 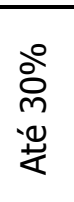 } & \multirow{4}{*}{$40,73 \%$} \\
\hline & Unidade II & 10,67 & $5,80 \%$ & & \\
\hline & Unidade III & 16,10 & $8,76 \%$ & & \\
\hline & Unidade IV & 25,99 & $14,14 \%$ & & \\
\hline & Unidade V & 35,68 & $19,41 \%$ & \multirow{4}{*}{ 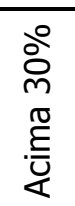 } & \multirow{4}{*}{$59,27 \%$} \\
\hline & Unidade VI & 19,42 & $10,57 \%$ & & \\
\hline & Unidade VII & 22,47 & $12,22 \%$ & & \\
\hline & Unidade VIII & 31,39 & $17,07 \%$ & & \\
\hline & Total & 183,83 & $100,00 \%$ & & \\
\hline \multirow{9}{*}{ BOM RETIRO } & Unidade I & 13,09 & $10,01 \%$ & \multirow{4}{*}{ 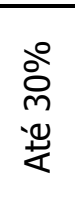 } & \multirow{4}{*}{$44,84 \%$} \\
\hline & Unidade II & 6,66 & $5,10 \%$ & & \\
\hline & Unidade III & 14,65 & $11,21 \%$ & & \\
\hline & Unidade IV & 24,20 & $18,51 \%$ & & \\
\hline & Unidade V & 22,56 & $17,26 \%$ & & \\
\hline & Unidade VI & 12,03 & $9,20 \%$ & pి & $55.16 \%$ \\
\hline & Unidade VII & 17,00 & $13,01 \%$ & $\stackrel{\mathbb{E}}{E}$ & $53,16 \%$ \\
\hline & Unidade VIII & 20,51 & $15,69 \%$ & $\overline{\mathrm{z}}$ & \\
\hline & Total & 130,71 & $100,00 \%$ & & \\
\hline
\end{tabular}

Fonte: Organização dos autores. 


\section{CONSIDERAÇÕES FINAIS}

De acordo com os parâmetros de relevo considerados na árvore de decisão os resultados da compartimentação geomorfométrica indicam que os bairros Da Glória, Velha Grande, Ribeirão Fresco, Nova Esperança e Bom Retiro apresentam maiores restrições à ocupação e, portanto, maior suscetibilidade à ocorrência de movimentos de massa. Quatro destes bairros estão situados na porção sul do município. Apesar desta constatação, ressalta-se que tal parte do território municipal é apontada como insegura para a ocupação urbana desde o primeiro Plano Diretor Municipal, no ano de 1977. Neste sentido, os resultados indicam um insucesso nas políticas públicas de planejamento urbano municipal.

Cabe mencionar que os bairros apontados pela compartimentação geomorfométrica como mais suscetíveis à ocorrência de movimentos de massa não são totalmente correspondentes aos indicados como mais afetados a partir do histórico de ocorrências atendidas pela Defesa Civil Municipal. Este fato pode estar relacionado a característica das ocorrências atendidas pela Defesa Civil Municipal, geralmente tratando de situações de risco ocasionados por intervenções humanas pontuais, o que necessariamente não depende de condições prévias de suscetibilidade do ambiente, sendo assim uma suscetibilidade criada e que, portanto, não pode ser apreendida pela escala de trabalho utilizada no geoprocessamento. Outro aspecto a ser considerado é a subnotificação, já que a Defesa Civil tende a ser acionada pela população mais carente, o que implica na ausência de registro de ocorrências em locais onde a população não depende do órgão para se reestabelecer.

Feita esta ressalva, cabe considerar que a compartimentação geomorfométrica se mostrou um método prático, eficiente e com baixo custo que permite indicar áreas mais suscetíveis à ocorrência de movimentos de massa. No que se refere à identificação de situações de risco, seria imnportante a complementação da análise por meio da obtenção de informações espaciais referentes ao processo de ocupação assim como das características socioeconômicas, o que aponta a necessidade de avanço em direção a caracterização da vulnerabilidade da área de estudo. 


\section{REFERÊNCIAS}

AEROIMAGEM S/A. Levantamento aerofotogramétrico do município de Blumenau. Santa Catarina: Aeroimagem S/A, 2003. Fotografia aérea. Escala 1:10.000.

AVILA, M. R. R.; MATTEDI, M. A. Desastre e território: a produção da vulnerabilidade a desastres na cidade de Blumenau/SC. Revista Brasileira de Gestão Urbana. Vol. 9. n. 2, p. 187- 202. maio/ago, 2017.

BIGARELLA, J. J.; BECKER, R. D.; PASSOS, E. Estrutura e origem das paisagens tropicais e subtropicais. Florianópolis: Ed. da UFSC, v. 3, 2003.

BLUMENAU. Lei Complementar No 489, de 25 de novembro de 2004. "Fixa o novo perímetro urbano do município de Blumenau...". Prefeitura Municipal de Blumenau, Blumenau, SC, 25 nov. 2004.2 Disponível em: https://leismunicipais.com.br/a/sc/b/blumenau/lei-complementar/2004/49/489/leicomplementar-n-489-2004-fixa-o-novo-perimetro-urbano-do-municipio-de-blumenau-sedee-do-distrito-de-vila-itoupava-e-estabelece-a-nova-divisao-de-bairros-2004-11-25-versaocompilada. Acesso: 20 jan. 2019.

BLUMENAU. Decreto No 8820, de 23 de novembro de 2008. "Declara situaçã̃o de calamidade pública no município de Blumenau". Prefeitura Municipal de Blumenau, Blumenau, SC, 23 nov. 2008.2 Disponível em: http://www.leismunicipais.com.br/a/sc/b/blumenau/decreto/2008/882/8820/decreto-n8820-2008-declara-situacao-de-calamidade-publica-no-municipio-de-blumenau-2008-1123.html. Acesso: 20 jan. 2013.

BLUMENAU. Decreto No 9337, de 03 de fevereiro de 2011. "Declara em situação anormal, caracterizada como situação de emergência, duas áreas localizadas no município de Blumenau afetadas por enxurradas e inundações bruscas". Prefeitura Municipal de Blumenau, Blumenau, SC, 03 fev. 2011a. Disponível em: https://leismunicipais.com.br/a/sc/b/blumenau/decreto/2011/933/9337/decreto-n-93372011-declara-em-situacao-anormal-caracterizada-como-situacao-de-emergencia-duasareas-localizadas-no-municipio-de-blumenau-afetadas-por-enxurradas-e-inundacoesbruscas.html. Acesso: 20 jan. 2013.

BLUMENAU. Decreto No 9356, de 11 de março de 2011. "Declara em situação anormal, caracterizada como situação de emergência, áreas localizadas nos bairros Texto Salto e Itoupava Central e no Distrito de Vila Itoupava, neste município, afetados por enxurradas e inundações bruscas". Prefeitura Municipal de Blumenau, Blumenau, SC, 11 mar. 2011b.

Disponível em:https://leismunicipais.com.br/a/sc/b/blumenau/decreto/2011/936/9356/decreto-n9356-2011-declara-em-situacao-anormal-caracterizada-como-situacao-de-emergenciaareas-localizadas-nos-bairros-testo-salto-e-itoupava-central-e-no-distrito-de-vila-itoupavaneste-municipio-afetados-por-enxurradas-e-inundacoes-bruscas Acesso: 20 jan. 2013.

BRASIL. Lei n. 6.766, de 19 de novembro de 1979. Dispõe sobre o Parcelamento do Solo Urbano e dá outras Providências. Presidência da República, Brasília, DF, 19 nov. 1979. Disponível em: http://www.planalto.gov.br/ccivil_03/leis/L6766.htm. Acesso em: 26 out. 2012. 
CARVAlHO, C. S.; GALVÃO, T. (org.). Prevenção de riscos de deslizamentos em encostas: Guia para elaboração de políticas municipais. Brasília: Ministério das Cidades/Cities Alliance, 2006.

COELHO NETTO, A. L. Catastrophic landscape evolution in a humid region (SE Brazil): inheritances from tectonic, climatic and land use induced changes. In Supplementi di Geografia Física e Dinâmica Quaternária, v.3, p. 21-48. 1999.

DIETRICH, W. E.; DUNNE, T. The channel head. In Beven, K. e Kirkby, M. (Eds.) Channel Network Hydrology. Chichester: John Wiley, 1993. p. 175-219.

DUNNE, T. Runoff production in a humid area. United Stated Department of Agriculture Report, ARS-41, 160 p. 1970.

FERNANDES, N. F.; AMARAL, C. P. do. Movimentos de massa: uma abordagem geológicogeomorfológica. In: GUERRA, A. J. T.; CUNHA, S. B. da (org.) Geomorfologia e meio ambiente, Rio de Janeiro: Bertrand Brasil, 1996. p. 123-194.

FERNANDES, N. F.; GUIMARÃES, R. F.; GOMES, R. A. T.; VIEIRA, B. C.; MONTGOMERY, D. R.; GREENBERG, H. Condicionantes geomorfológicos dos deslizamentos nas encostas: avaliação de metodologias e aplicação de modelo de previsão de áreas susceptíveis. Revista Brasileira de Geomorfologia, v. 2, n.1, p. 51-71, 2001.

FLORENZANO, T. G. Geomorfologia: conceitos e tecnologias atuais. Oficina de Textos: São Paulo, 2008.

GONÇALVES, U. S.; FRANCISCO, C. N. Análise espacial das variáveis geomorfométricas e movimentos de massa na região serrana fluminense. Revista Brasileira de Cartografia, 2016. Vol. 68. n. 9, Out. 2016. P. 1839-1851.

GUERRA, A. J. T.; CUNHA, S. B. da; (Orgs). Geomorfologia e meio ambiente. Rio de Janeiro: Bertrand Brasil, 1996, 394 p.

HERRMANN, M. L. de P. (org.) Atlas de desastres naturais do estado de Santa Catarina. Secretaria de Estado de Segurança Pública e Defesa do Cidadão. Florianópolis, 2006. Disponível em: http://www.cfh.ufsc.br/ gedn/atlas/Atlas_Ceped.pdf Acesso em: 20 fev. 2011.

INSTITUTO BRASILEIRO DE GEOGRAFIA E ESTATÍSTICA. Censo 2010: resultados divulgados no Diário Oficial da União em 04.11.2010. Disponível em: http://www.ibge.gov.br/home/estatistica/populacao/censo2010/resultados_dou/SC2010.p df Acesso em: 08 out. 2011.

NSTITUTO BRASILEIRO DE GEOGRAFIA E ESTATÍSTICA. Aglomerados Subnormais: primeiros resultados (download). In: Censo. 2010b. Disponível em: http://www.ibge.gov.br/home/estatistica/populacao/censo2010/aglomerados_subnormais/ agsn2010.pdf. Acesso em: 16 nov. 2013.

KORMANN, T. C. Ocupação de encostas no município de Blumenau - SC: Estudo da formação das áreas de risco a movimentos de massa. 2014. 147 p. Dissertação (Mestrado em Geografia) - Universidade Federal do Rio Grande do Sul, Porto Alegre, 2014. 
McBRATNEY, A. B.; MENDONÇA-SANTOS, M. L.; MINASNY, B. On digital soil mapping. Geoderma, v. 117, 2003. p. 3-52.

MOORE, I.D., GRAYSON, R.B., LADSON, A. R. Digital terrain modeling: A review of Hydrological, geomorphological and biological applications. Hydrological Processes, $v$. 5, 1991. p. 3-30.

NUNES, L H. Urbanização e desastres naturais. São Paulo: Oficina de Textos, 2015.

POZZOBON, M. Análise da suscetibilidade a deslizamentos no município de Blumenau/SC: uma abordagem probabilística através da aplicação da técnica de pesos de evidências. 2013. 139 f. Tese (Doutorado em Ciências Florestais). Universidade Federal do Paraná, Curitiba, 2013.

ROBAINA, L. E. de S. Espaço urbano: relação com os acidentes naturais no Brasil. Ciência e Natura. Santa Maria, v. 5, n. 2; dez. 2008. p. 93-105.

ROCHA, C. H. B. Geoprocessamento: tecnologia transdisciplinar. Juiz de Fora, MG: Ed. do Autor, 2000.

SANTOS, G. F. dos. Vale do Garcia (Blumenau - SC): análise climato-geomorfológica e a repercussão dos episódios pluviais no espaço urbano. São Paulo, 1996. Tese de Doutorado em Geografia. Universidade de São Paulo, 1996. 362 p.

SILVA, J. X.; ZAIDAN, R. T. (Org.). Geoprocessamento \& análise ambiental: aplicações. Rio de Janeiro: Bertrand Brasil, 2004.

SILVEIRA, C. T. OKA-FIORI, C.; SANTOS, L. J. C; SIRTOLI, A. E.; SILVA, C. R.; BOTELHO, $M$. F. Soil prediction using artificial neural networks and topographic attributes. Revista Geoderma 195-196, p. 165-172. 2013.

TOMINAGA, L. K. Desastres naturais: por que ocorrem? In: TOMINAGA, L. K. et. al. (orgs.) Desastres naturais: Conhecer para prevenir. São Paulo: Instituto Geológico, 2009. P. 13-23.

VALERIANO, M. M. Curvatura vertical de vertentes em microbacias pela análise de modelos digitais de elevação. Revista Brasileira de Engenharia Agrícola e Ambiental, Campina Grande, v.7, n.3, 2003. p. 539-546, 2003. Disponível em: http://dx.doi.org/10.1590/S1415-43662003000300022. Acesso em: 12 nov. 2018.

VALERIANO, M. M.; CARVALHO JÚNIOR, O, A. Geoprocessamento de modelos digitais de elevação para mapeamento da curvatura horizontal em microbacias. Revista Brasileira de Geomorfologia, v 4, n.1, p.17-29, 2003. 